\title{
Assess teachers and students' interaction in campus
}

\author{
WHE-MIN WANG \\ Industrial Management Department \\ Oriental Institute of Technology \\ No.58, Sec. 2, Sihchuan Rd., Banciao Dist., New Taipei City, 22061 \\ TAIWAN, R.O.C. \\ and \\ Department of Management Science \\ Tamkang University \\ No. 151, Yingzhuan Rd., Tamsui Dist., New Taipei City, 25137 \\ TAIWAN, R.O.C. \\ HORNG-JINH CHANG \\ Department of Management Science \\ Tamkang University \\ No. 151, Yingzhuan Rd., Tamsui Dist., New Taipei City, 25137 \\ TAIWAN, R.O.C. \\ TAN-NI WANG \\ Department of Gerontological Health Care \\ National Taipei University of Nursing and Health Sciences \\ No.58, Sec. 2, Sihchuan Rd., Banciao Dist., New Taipei City, 22061 \\ TAIWAN, R.O.C
}

\begin{abstract}
There are 3 combinations of teacher-student interaction in school, for the purpose to understand what Interactional deficiency happened in campus, we examined these 3 combinations, 358 college students joined the investigated to find out what they want and what bother them most. We found that there really problems between teachers and students. Besides, from co- authorship network analysis, we found there are also quite a few gaps among college teachers. We collected co-authorship data from 85 journal papers in the field of industrial and management science (IMS) with a time span of twenty years (1997-2016). A bibliometric network is constructed and UCINET 6 applied to calculate three centrality measures (out-degree, in-degree, and betweenness) for individual authors in this network. Also discussed the two subjects I taught to find out students' learning effectiveness. The results confirm our argument and the mechanism is discussed.
\end{abstract}

Key-Words: - Factor analysis, Learning stress, Social-linkage, Co-authorship, Social Network Analysis

Received: November 8, 2019. Revised: May 2, 2020. Accepted: May 19, 2020. Published: May 29, 2020.

\section{Introduction}

For a long time, universities have been the place to cultivate social elites. And university teachers have occupied a very important position, and they have a heavy responsibility. But most teachers always frustrated on how to play their role. So how to judge a teacher's performance competent? When a teacher is recruited into a school, there are three jobs for them; one is teaching, the other is tutoring students, and the third is doing research and publishing papers. What is the proportion of these three? It depends on each school.

How to play his or her role well is controversial? The interaction in school between teachers and students, we can summarize as three types, that is: teachers, students and teacher-student. Therefore, we are going to examine the performance of campus teachers on this paper. 
As network analysis emerge, there finally comes a better tool to evaluate teachers' performance. So we will review teachers' research and publishing papers in 1997-2016, the department of Industrial Management (IM) of Oriental Institute of Technology(OIT). And also students' performance in school. 2017 ICAMCS I presented "Breakthrough on Technical and Vocational Education of Taiwan: Take Oriental Institute of Technology as an Example ", which discussed source of pressure, and also discussed different factors. It is about students' learning pressure. Also I would like to present two subjects, which is Economic and Management I taught in class, data accumulate over 8years, the average score shows students' learning status.

\section{$2 \quad$ Literature Review}

Research shows that appropriate connectivity in wellmanaged networks within organizations can have a substantial impact on performance, learning, and innovation [1]. A working model of transdisciplinary scientific collaboration was proposed by Stokols, et al [2]. This working model includes three major faces: antecedents, intervening processes, and outcomes. Stokols, indicated that the intervening processes have received little or no empirical attention in studies. The intervening processes include the influence of social or interpersonal cohesion among center members on their efforts to achieve intellectual or scientific integration of their ideas.

Members in a department are working in an evolving network of communication from which interactive learning and knowledge leading to innovations. Koseoglu [3] indicated the collaboration could strengthen the network of the research community to consolidate the disciplines, disseminate knowledge, and shift expansion and transformation in the discipline. In recent years, a number of studies have been conducted to reveal the evolution of collaboration and networks and to identify key actors as either individuals or groups and to demonstrate the relationships among these actors, or relationships between indicators of these networks and actors' outputs. The collaboration based on knowledge domain has been assessed in a number of studies via qualitative and quantitative methods. These research methods posit the tension exists between the organization and its environment, and individuals and their relations within the organization [4].
Abbasi, Chung, and Hossain [5] revealed that scholars with efficient collaboration networks who maintain a strong co-authorship relationship with one primary co-author within a group of linked co-authors perform better than those researchers with many relationships to the same group of linked co-authors. $\mathrm{Li}$, Liao, and Yen [6] found that co-authoring with prolific scholars helps researchers develop centralities and, in turn, generate higher numbers of citations. They also indicated that researchers with longer publishing tenure tend to have higher degree centrality, and when they collaborate more with different scholars, they achieve more closeness and betweenness centralities, but risk being distrusted by prolific scholars and losing chances to co-author with them.

Li, Zhang, Luo, and Jiang [7] indicated that interpreting the formation of co-author networks is an interesting task since it can uncover the human behavior reasons why the co-author network can form. In this research, not only the visualization of the coauthorship network is illustrated, but it also takes into consideration the latent daily interaction. Networks can be analyzed to look for information about the network as a whole, or to look for individuals of interest, such as which person is most central or marginalized in a network. We tended to evaluate our graphs for information about individual behavior and as a whole at the network level.

Social network analysis stems from investigations by Moreno [8] and Lewin [9] on the social relations and network characteristics of individuals. It is one robust method for studying the mechanisms of communication and collaboration among members in a department. It has been widely utilized in various fields, such as sociology [10], anthropology [11], and political science [8]. In the past three decades, social network analysis has been increasingly advocated as a key approach to addressing network organization issues in management [12]. A visual representation of a network provides a rich understanding of complex academic researcher groups.

Young people's problem continues to happen again, the status of young people and the prospects for the future is worrisome. Ji and Zhang [13] found the positive correlation between study conditions and mental stresses of college students. An online survey by Votta and Benau [14] found that academic concerns were a primary source of stress. When stress is perceived negatively or becomes excessively, it can affect both health and academic performance [15]. 
University students often attempt to control and reduce their stress through avoidance, religious and social support, or positive reappraisal [16]. Another research [7] indicated that secondary school students had a medium level of stress and the significant sources of stress included academic, intra-personal and environmental. An investigation by Beiter et al., [12] indicated that the top three concerns were academic performance, pressure to succeed, and postgraduation plans.

With the development of science, more and more researches have to be completed by the cooperation of multiple scientists. The growing complexity of science and its specialization require that research be based on collaborations among teachers with different skills and backgrounds [17]. Research collaboration is a key mechanism for knowledge diffusion within research communities [18]. Studies find that research collaboration can be influenced by numerous. Some researchers define it as a process of integrating different bodies of knowledge. Integration also entails social interaction, including negotiation of conflict and arguments.

\section{Co-authorship network analysis of the Participants}

Co-authorship is one of the most tangible and welldocumented forms of scientific collaboration, almost every aspect of scientific collaboration networks can be reliably tracked by analyzing co-authorship networks by bibliometric methods [19]. Coauthorship network analysis is a powerful tool for strategic planning of research, development and capacity building programs [20]. Our research focus on statistical database of co-author group membership consists of 59 members. Although teaching staff is 10 members right now, but as time in and time out, someone joined the staff in sometime while some other left the unit, all journal papers survey accumulated was 85 .

We examine their publications in recent 2 decades which were collected from the bibliographic search on website. For each article, the authors' names were collected for co- authorship network analysis.

As table 1. shows, two of these 59 participants are prolific. They have published 24 and 31 papers, over half of all the published papers. There were 33 persons having no papers published as the first author.

Network relationships reveal collaboration between members, it forming strategic partnerships and alliance, in the same time; also it has the function of communication, offer information, problem solving and innovation that is why people choose move toward this bondage. For exploring their collaboration, further analysis shown on Table 2. It presents the frequencies of in-degree, out-degree, and betweenness. Maximum of in-degree and out-degree is 30 and 55 respectively. Since we use in-degree as an indicator of invitation, it means there is one person having received 30 invitations as a co- author. Outdegree used as an indicator of inviting others to be as a co-author, and it means the highest prolific member has invited 55 persons as co-authors during these 2 decades. Obviously, the prolific members are the star of co-authorship network.

The variable betweenness is between 0 and 7.63. Interactions between two nonadjacent actors have to depend on the other actors. The persons with higher betweenness are these "other actors". In addition, these "other actors" potentially have some control over the interactions between the two nonadjacent actors. As figure 1, these "other actors" are the one between the others. Obviously, they have some control over paths in the graph. Since they are between the others, they are more central and play most important roles in the network.

Table 1 Papers published

\begin{tabular}{|c|c|c|}
\hline No. of paper & Frequency & $\%$ \\
\hline 0 & 33 & 55.9 \\
\hline 1 & 10 & 16.9 \\
\hline 2 & 6 & 10.2 \\
\hline 3 & 2 & 3.4 \\
\hline 4 & 2 & 3.4 \\
\hline 5 & 1 & 1.7 \\
\hline 6 & 2 & 3.4 \\
\hline 9 & 1 & 1.7 \\
\hline 24 & 1 & 1.7 \\
\hline 31 & 1 & 1.7 \\
\hline
\end{tabular}

Table 2 Frequency of in-degree, out-degree, and betweenness

\begin{tabular}{|c|c|c|c|c|}
\hline Variables & Min & Max & Mean & SD \\
\hline in-degree & 0 & 30 & 3.51 & 6.00 \\
\hline out-degree & 0 & 55 & 3.51 & 8.66 \\
\hline betweenness & 0 & 7.63 & 0.47 & 1.39 \\
\hline
\end{tabular}


Table 3 Frequency of in-degree

\begin{tabular}{|c|c|c|}
\hline in-degree & Frequency & $\%$ \\
\hline 0 & 8 & 13.6 \\
\hline 1 & 23 & 3.0 \\
\hline 2 & 11 & 18.6 \\
\hline 3 & 2 & 3.4 \\
\hline 4 & 5 & 8.5 \\
\hline 6 & 2 & 3.4 \\
\hline 7 & 1 & 1.7 \\
\hline 8 & 1 & 1.7 \\
\hline 10 & 1 & 1.7 \\
\hline 19 & 1 & 1.7 \\
\hline 27 & 2 & 3.4 \\
\hline 30 & 1 & 1.7 \\
\hline
\end{tabular}

Table 4 Frequency of out-degree

\begin{tabular}{|c|c|c|}
\hline out-degree & Frequency & $\%$ \\
\hline 0 & 33 & 55.9 \\
\hline 1 & 3 & 5.1 \\
\hline 2 & 8 & 13.6 \\
\hline 3 & 2 & 3.4 \\
\hline 4 & 2 & 3.4 \\
\hline 6 & 3 & 5.1 \\
\hline 7 & 1 & 1.7 \\
\hline 8 & 1 & 1.7 \\
\hline 10 & 1 & 1.7 \\
\hline 12 & 1 & 1.7 \\
\hline 14 & 1 & 1.7 \\
\hline 20 & 1 & 1.7 \\
\hline 30 & 1 & 1.7 \\
\hline 55 & 1 & 1.7 \\
\hline
\end{tabular}

Table 5 In-degree and out-degree

\begin{tabular}{|c|c|c|c|c|c|c|c|c|c|c|c|c|c|}
\hline \multirow{2}{*}{$\begin{array}{c}\text { Out- } \\
\text { degree }\end{array}$} & \multicolumn{10}{|c|}{ In-degree } \\
\cline { 2 - 15 } & 0 & 1 & 2 & 3 & 4 & 5 & 6 & 7 & 8 & 10 & 19 & 27 & 30 \\
\hline 0 & 0 & 21 & 7 & 1 & 1 & 2 & 0 & 0 & 1 & 0 & 0 & 0 & 0 \\
\hline 1 & 1 & 0 & 1 & 0 & 1 & 0 & 0 & 0 & 0 & 0 & 0 & 0 & 0 \\
\hline 2 & 2 & 2 & 1 & 0 & 3 & 0 & 0 & 0 & 0 & 0 & 0 & 0 & 0 \\
\hline 3 & 2 & 0 & 0 & 0 & 0 & 0 & 0 & 0 & 0 & 0 & 0 & 0 & 0 \\
\hline 4 & 1 & 0 & 0 & 0 & 0 & 0 & 1 & 0 & 0 & 0 & 0 & 0 & 0 \\
\hline
\end{tabular}

\begin{tabular}{|c|c|c|c|c|c|c|c|c|c|c|c|c|c|}
\hline 6 & 1 & 0 & 2 & 0 & 0 & 0 & 0 & 0 & 0 & 0 & 0 & 0 & 0 \\
\hline 7 & 0 & 0 & 0 & 0 & 0 & 0 & 0 & 1 & 0 & 0 & 0 & 0 & 0 \\
\hline 8 & 0 & 0 & 0 & 0 & 0 & 0 & 0 & 0 & 0 & 0 & 1 & 0 & 0 \\
\hline 10 & 0 & 0 & 0 & 0 & 0 & 0 & 0 & 0 & 0 & 1 & 0 & 0 & 0 \\
\hline 12 & 0 & 0 & 0 & 1 & 0 & 0 & 0 & 0 & 0 & 0 & 0 & 0 & 0 \\
\hline 14 & 0 & 0 & 0 & 0 & 0 & 0 & 0 & 0 & 0 & 0 & 1 & 0 & 0 \\
\hline 20 & 1 & 0 & 0 & 0 & 0 & 0 & 0 & 0 & 0 & 0 & 0 & 0 & 0 \\
\hline 30 & 0 & 0 & 0 & 0 & 0 & 0 & 0 & 0 & 0 & 0 & 0 & 1 & 0 \\
\hline 55 & 0 & 0 & 0 & 0 & 0 & 0 & 0 & 0 & 0 & 0 & 0 & 0 & 1 \\
\hline
\end{tabular}

As table 3, there are 8 persons with in-degree of 0 . It means they were not being invited as co-authors. As table 4 , there are 33 persons with out-degree of 0 . It means they have not invited any person as co-author. If someone has zero in-degree or out-degree, how is the publication? For further scrutiny this phenomenon, the cross table of in-degree and out-degree is constructed, as table 5. This table shows that there is not a person with both zero out-degree and in-degree. In the first column, 8 persons with zero in-degree have at least 1 out-degree. They have invited 1-2 persons as their co-authors. In addition, in the first line, within 33 persons with zero out-degree, there are 21 persons having one invitation, 7 persons having 2 invitations, and the others having more invitations from others. The phenomenon shown as table 5, 41 persons have zero in-degree or zero out-degree, indicates these members do not have equal invitation and being invited. This table also shows that a person with more in-degree has more out-degree. Obviously, the communication interaction is in two ways. The more persons you invite; the more persons will invite you as co-authors.

Figure 1 demonstrates the co-authorship or 59 members in the teaching unit. These 59 members did not construct as one group. There are 2 pairs, 9-person group, and the largest group of 46 persons. In the largest group, LDS, SKK, YYY, KYH with the highest betweenness are in the central. Key persons as LDS, SKK, YYY and KYH play as the roll of stars in this department. If they left, what would happen? Figure 2, and 3 will tell us the results. As Fig. 2, when the person with the highest betweenness is deleted, 5 isolates appear and the original largest group (46 persons) separates into 2 groups (5 persons and 35 persons). These 5 isolated persons have not any connection with others.

When we continue to delete the 2nd high 
betweenness, 16 isolates, 2 pairs, and 1 triangle appear. There are still 3 groups, with less persons.

When we continue to delete the 3rd high betweenness, more isolates, pairs, and triangles appear. If all these four higher betweenness are deleted, 21 isolates, 5 pairs, 2 triangles, and 3 groups left. It has no influence on the original 2 pairs, and 9person group. They exist in the same state. The result shows that the stars as a leadership in an organization are crucial and irreplaceable. This result summarized as table 6 .

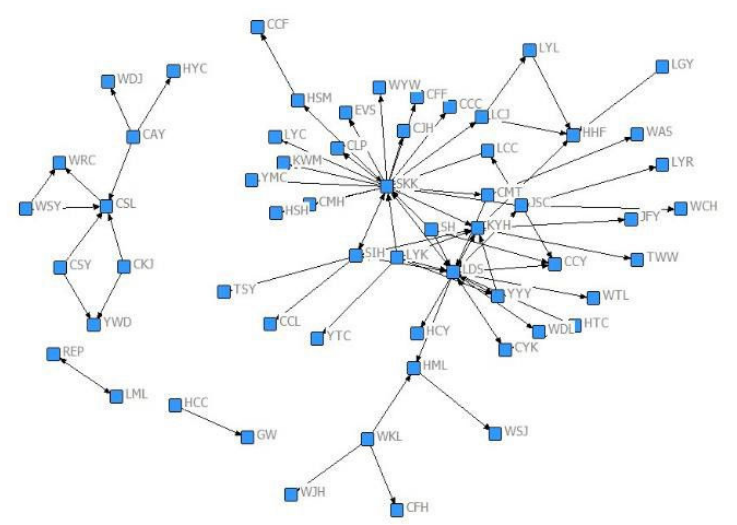

Fig. 1 Co-authorship network

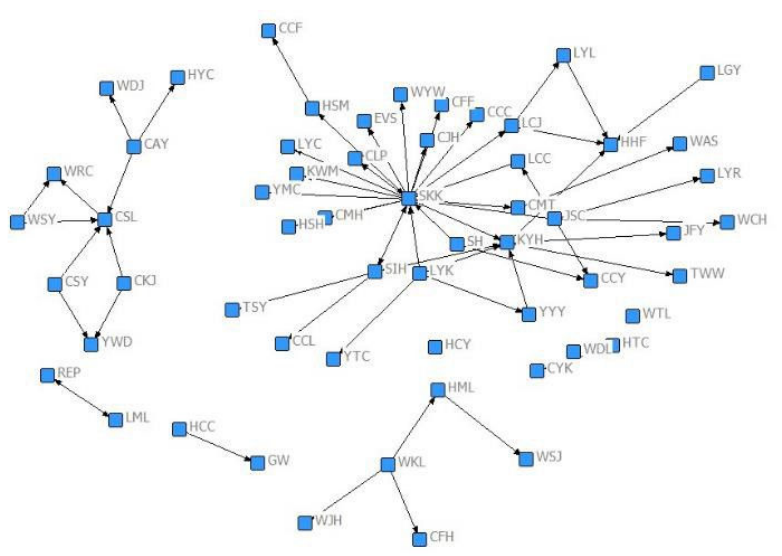

Fig. 2 Co-authorship network (the highest betweenness deleted)

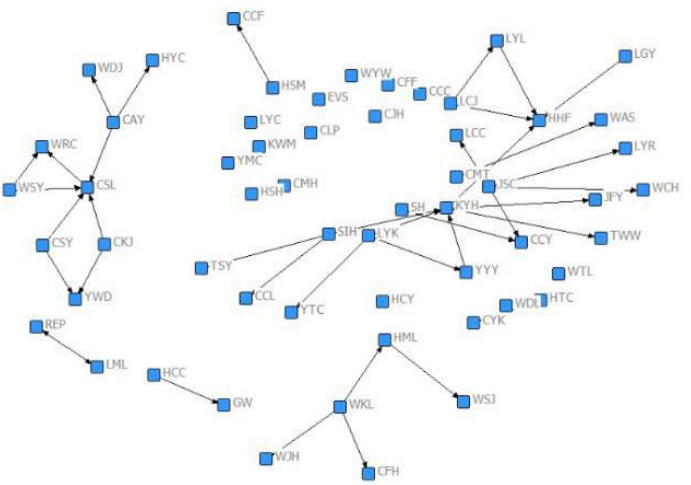

Fig. 3 Co-authorship network (the 2nd high betweenness deleted)

Generally, teaching unit in academic is different in network society, leader of the unit plays either communication role or convey the message from hierarchical level. It also can be bottleneck when the leader is not full engagement and de- energizing. In the circumstance as this all members in the teaching unit turn out to be isolated and peripheral. All crews did his own research or teaching without knowing what happens in the outside world. Sometimes it may jeopardize the whole community.

Table 6 Summary of the evolution network

\begin{tabular}{|c|c|c|c|c|c|}
\hline Deleted & group & isolate & pair & triangle & total \\
\hline None & $2(9,46)$ & 0 & 2 & 0 & 59 \\
\hline $1^{\text {st }}$ & $3(9,5,35)$ & 5 & 2 & 0 & 58 \\
\hline $2^{\text {nd }}$ & $3(9,5,16)$ & 16 & 4 & 1 & 57 \\
\hline $3^{\text {rd }}$ & $3(9,5,4)$ & 18 & 4 & 4 & 56 \\
\hline
\end{tabular}

Total $=9+46+2 * 2$ (pair) $=59$

Total $\left(1^{\mathrm{st}}\right)=9+5+35+5$ (isolate $)+2 * 2($ pair $)=58$

Total $\left(2^{\text {nd }}\right)=9+5+6+6$ (isolate $)+2 * 4$ (pair)

$+3 * 1$ (triangle $)=57$ Total $\left(3^{\text {rd }}\right)=9+5+4+18$ (isolate)

$+2 * 4$ (pair) $+3 * 4($ triangle $)=56$

\section{Source of stress}

The research paper of stress of students' come from" Breakthrough on Technical and Vocational Education of Taiwan: Take Oriental Institute of Technology as an Example [21] “, which I presented in 2017ICAMCS, International Conference on Applied Mathematics and Computer Science, Rome, Italy, January 27-29. Rating scale design by Chang [22] [23], investigated time period 
from 2015-2018, 358 students joined the survey.

Table7 was extracted from factor analysis, arrangement is based on loading value level of component 1. "Students care about the time they communicate with teacher, they also expected there will be positive feedback". This item is the desperate need of students, most teachers know that they need to be patient and listen to students' voice. In Table8, we compare these six factors and found that there are some other problems students got to face, three factors were higher than 4 , it means that school authority should pay attention to them and solve these problems.

Table 7 Students' communication with teachers

\begin{tabular}{|c|c|c|}
\hline \multicolumn{3}{|c|}{ Component 1 } \\
\hline item & $\%$ & teachers' problem \\
\hline 22 & 0.777 & $\begin{array}{l}\text { teachers and students do not have two-way } \\
\text { communication }\end{array}$ \\
\hline 25 & 0.773 & $\begin{array}{l}\text { teachers seldom provide students with } \\
\text { positive feedback }\end{array}$ \\
\hline 23 & 0.767 & $\begin{array}{l}\text { teachers' teaching content cannot be } \\
\text { expressed clearly in class }\end{array}$ \\
\hline 24 & 0.747 & teachers offer little helping to their trouble \\
\hline 38 & 0.745 & bridging courses between unsatisfactory \\
\hline 21 & 0.735 & Teacher' lectures and textbooks vary widely \\
\hline 31 & 0.73 & teachers seldom encourage students to think \\
\hline
\end{tabular}

Table 8 Source of stress comparison

\begin{tabular}{|c|c|c|}
\hline Source of stress & Mean & SD \\
\hline $\begin{array}{c}\text { communication } \\
\text { with teachers }\end{array}$ & 3.0403 & 1.42141 \\
\hline learning anxiety & 4.0649 & 1.61952 \\
\hline $\begin{array}{c}\text { Students' } \\
\text { confidence }\end{array}$ & 3.8149 & 1.34274 \\
\hline about curriculum & 4.1390 & 1.56369 \\
\hline part-time job & 3.2190 & 1.26174 \\
\hline $\begin{array}{c}\text { social } \\
\text { environment }\end{array}$ & 4.1937 & 1.58896 \\
\hline
\end{tabular}

\section{Two subjects' discussion}

Also from two subjects in my class past over 8 years, Table1. And Table 2. record students' performance in 8 years of the course I taught, the average score around 60-70 interval, shows as Fig 4. And Fig 5. The trend shows decreasing, and it means that students' learning in class are getting worse.

\subsection{Subject of management}

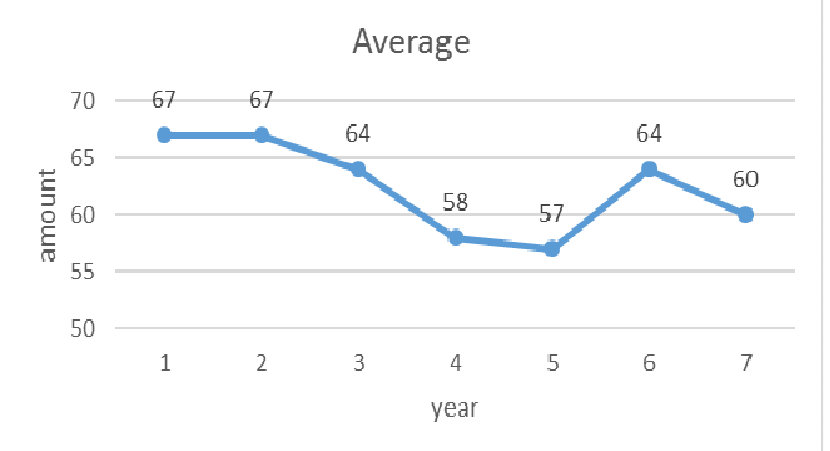

Fig 4. Average score of Management

Table 9. Students' performance in Subject of Management

\begin{tabular}{|c|c|c|c|c|c|c|}
\hline Year & students & Fail & Average & S.D. & Highest & Lowest \\
\hline 101 & 62 & 10 & 67 & 11.37 & 85 & 40 \\
\hline 102 & 53 & 15 & 67 & 15.88 & 90 & 45 \\
\hline 103 & 58 & 10 & 64 & 10.67 & 87 & 32 \\
\hline 104 & 49 & 12 & 58 & 18.73 & 93 & 0 \\
\hline 105 & 47 & 13 & 57 & 15.22 & 87 & 30 \\
\hline 106 & 50 & 9 & 64 & 16.77 & 95 & 18 \\
\hline 107 & 45 & 10 & 60 & 11.73 & 82 & 20 \\
\hline 108 & 42 & 10 & 61 & 9.63 & 78 & 30 \\
\hline
\end{tabular}

\subsection{Subject of Economic}

Table 10 Students' performance in Subject of Economic

\begin{tabular}{|c|c|c|c|c|c|c|}
\hline Year & students & Fail & Average & S.D. & Highest & Lowest \\
\hline 100 & 60 & 8 & 66 & 12.28 & 89 & 30 \\
\hline 101 & 59 & 8 & 64 & 11.21 & 83 & 30 \\
\hline 102 & 54 & 7 & 68 & 11.31 & 88 & 30 \\
\hline 103 & 55 & 8 & 63 & 9.59 & 90 & 41 \\
\hline 104 & 53 & 11 & 61 & 15.01 & 88 & 26 \\
\hline 105 & 41 & 6 & 65 & 15.3 & 94 & 16 \\
\hline $\mathbf{1 0 6}$ & 42 & 12 & 57 & 18.12 & 87 & 12 \\
\hline $\mathbf{1 0 7}$ & 46 & 17 & 54 & 13.3 & 80 & 20 \\
\hline
\end{tabular}




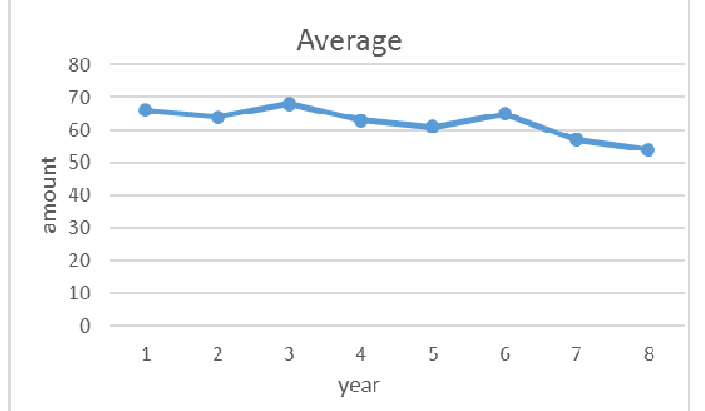

Fig 5. Average score of Economic

\section{Conclusion}

From above we find out the relationship between teacher and student in school seems not good at all, students attributed all problems to their teachers. Students think about their teachers as:" Teachers often give a negative evaluation, blaming or criticizing", "Teachers treat students with a lack of respect ", "Teachers will not accept the views of students", "Relationship with teachers is unfriendly". Whether teachers know the reaction of students or they just concentrate on their paper publishing is worrisome.

Teachers contribute their energy to specific field of publication, and the authority also encourage them to do so, let the students fall into the disappointment of frustration. If teachers do not join the co-authors network social-linkage, individuals can become isolated and trapped in helpless peripheral.

Publication of papers is required in academic society and technical \& vocational schools recently in Taiwan and elsewhere of the world. Crewmembers of teaching unit joining co-authorship are for the purpose to increase the quality and quantity of papers. When the trend is forming, everyone is chasing the link. However, the premise is that there is a good teacher-student relationship. The priority is: first teaching, the second is counseling, then is research.

The current developments have confused us all. Students are also helpless; no wonder the school will fall into chaos. The author's intention in writing this essay is to awaken public awareness so as to eliminate the lack of interaction between teachers and students, enabling students to learn happily and scholars to concentrate on research.

\section{Reference}

[1] R Cross, SP Borgatti, A Parker- California management ..., 2002 - journals.sagepub.com.
[2] Stokols, D., Fuqua, J., Gress, J., Harvey, R., Phillips, K., Baezconde-Garbanati, L., et al. 2003. Evaluating Transdisciplinary Science. Nicotine \& Tobacco Research, 5, S21-S39 (2003).

[3] Koseoglu, M. A. 2016. Growth and Structure of Authorship and Co-authorship Network in the Strategic Management Realm: Evidence from the Strategic Management Journal. Bus. Res. Q. 19, 153 - 170 (2016)

[4] Guerras Martin, L. A., Madhok, A., MontoroSanchez, A. The Evolution of Strategic Management Research: Recent Trends and Current Directions. Bus. Res. Q. 17, 69-76 (2014)

[5] Abbasi, A., Chung, K.S.K., Hossain, L. 2012. Egocentric analysis of co-authorship network structure, position and performance. Information Processing and Management, 48, 671-679 (2012).

[6] Li, E.Y., Liao, C.H., Yen, H.R. 2013. Coauthorship networks and research impact: A social capital perspective. Research Policy, 42, $1515-1530$ (2013)

[7] Li, Y., Zhang, D., Luo, P., Jiang, J. 2017. Interpreting the formation of co-author networks via utility analysis. Information Processing and Management, 53, 624-639

[8] Moreno, J.L. 1934. Who Shall Survive? Foundations of Sociometry, Group Psychotherap, and Sociodrama. Nervous and Mental Disease Publishing Co., Washington, D.C. (1934)

[9] Lewin, L.: Principles of Topological Psychology. McGraw- Hill, New York, NY. (1936)

[10] Simmel, G., Wolff, K.H.: The Sociology of Georg Simmel. The Free Press, New York. (1950)

[11] Tichy, N.M., Tushman M.L., Fombrun, C. 1979. Social network analysis for organizations. Acad. Manag. Rev. 4(4), 507-519 (1979)

[12] Beiter, R., Nash,R., McCrady, M., Rhoades, D., Linscomb, M., Clarahan, M.,\& Sammut, S.. "The prevalence and correlates of depression, anxiety, and stress in a sample of college students," Journal of Affective Disorders, 173, 90-96. (2015)

[13] H. Ji, L Zhang. "Research on college students' stresses and coping strategies," Asian social Science, vol. 7, pp. 30-34, 2011. 
[14] Votta, R. J., \& Benau, E.M. "Sources of stress for pharmacy students in a nationwide sample," Currents in Pharmacy Teaching and Learning, 6, 675-681 (2014).

[15] Campbell, R . L , \& Svenson, L.W. "Perceived le $v$ e $l$ of stress among university undergraduate students in Edmonton", Canada. Perceptual and Motor Skills, 75, 552-554 (1992)

[16] Mattlin, J.A., Wethington, E., \& Kessler, R.C. Situational determinants of coping and coping effectiveness. Journal of Health and Social Behavior, 31, 103-122 (1990).

[17] De Stefano, D., Fuccella, V., Vitale, M.P. Zaccarin, S. 2013.The Use of Different Data Sources in the Analysis of Co- authouship Networks and Scientific Performance. Soc. Netw.35, 370-381, 2007.

[18] Heinze, T., Kuhlmann, S. 2008. Across Institutional Boundaries?Research Collaboration in German Public Sector Nanoscience.Research Policy, 37, 888-899 (2008)

[19] Liu,Xiaoming, Bollen, J., Nelson, M. L., \& Van de Sompel, H. 2005. Co-authorship networks in the digital library research community.
Information Processing \& Management, 41, 1462-1480 (2005)

[20] Morel, Carlos Medicis, Serruya, S. J., Penna, G. O., \& Guimarães, R. 2009. Co-authorship network analysis: a powerful tool for strategic planning of research, development and capacity building programs on neglected diseases. PLos Negl Trop Dis, 3, e501 (2009)

[21] Whe-Min Wang, ICAMCS 2017,', Breakthrough on Technical and Vocational Education of Taiwan: Take Oriental Institute of Technology as an Example", Int.Conf. on Applied Mathematics and Computer Science, Rome, Italy, January $27-$ 29, 2017.

[22] Horng Jinh Chang, "Sampling method and survey analysis: concept, design, analysis, examples", Taipei: Hwa-Tai Publishing, 2009/01.

[23] Wang Whe-min." Technical institute student's psychological stress investigation reflect on the role of the teachers'." 2014 International Symposium on civic literacy and general education, p302-304 (2014) 